\title{
Radiation-resistant materials based on mica in the construction industry
}

\author{
Tamara Shishelova ${ }^{1, *}$, and $V$. Zhitov ${ }^{1}$ \\ ${ }^{1}$ Irkutsk National Research Technical University, 664074, Lermontova str., 83, Irkutsk, Russia
}

\begin{abstract}
Burial of radioactive waste is an urgent contemporary problem. The development of materials for the disposal of radioactive waste is also topical. In this paper, we consider the possibility of using mica to solve these problems. Mica has been known for a long time and studied by researchers from almost all countries of the world. The areas of its use are constantly expanding and renewing. Mica has high electrical insulation properties. Because of this, the field of application of mica was the electrotechnical industry for a long time. Currently, the range of using mica is quite wide. In this paper, attention is paid to the relatively promising areas of its use. The possibility of using composite materials based on mica as materials for protection against radioactive emissions and disposal of radioactive waste is considered. The object of the study: samples of a composite material based on mica, or the mikalexs. The method of recording ionizing radiation and the mass spectroscopic method were used to study linear coefficients of $\mu$ attenuation from gamma radiation of mikalexes on the basis of various micas after bombardment with $5 \mathrm{MeV}, 10 \mathrm{MeV}, 25 \mathrm{MeV}$ electron beams. We used: a cesium source of $\gamma$-radiation with $E=0.661 \mathrm{MeV}$ and a cobalt source with $\mathrm{E}=1.25 \mathrm{MeV}$. Research results on the $\mu$ linear attenuation coefficients on $\gamma$-radiation of mikalexes based on various micas after their bombardment with electron fluxes showed that electron bombardment increases the penetrating power of gamma radiation in the mikalex. The dependence of the coefficient of linear attenuation on the type of mica used was determined. A new field of use of composite materials based on mica (micalex) for radiation protection and the disposal of radiation waste and their use in ultrahigh vacuum.
\end{abstract}

\section{Introduction}

Burial of radioactive waste is an actual problem of our time. Radioactive wastes are nuclear materials and radioactive substances, the further use of which is not foreseen. Waste is the main long-lived source of radiation associated with nuclear energy. According to the International Atomic Energy Agency (IAEA), it has been established that more than 200,000 tons of spent nuclear fuel have been accumulated in the world. Each year, 5-6 tons of spent nuclear fuel are added. This problem is also an actual problem for the Irkutsk region. In the region, there are two enterprises for the disposal of radioactive waste, namely the "Rodon" and the electrochemical plant in Angarsk (AECC) [1].

* Corresponding author: tamara.shishelova@gmail.com 
The disposal of radioactive waste is carried out in special facilities, burial grounds, which require the use of special radiation-resistant materials. In most cases, various concrete and reinforced concrete structures are used, now large work is being done to dispose of radioactive waste. Despite this, many of the problems remain, most of them are the development of radioactive materials and materials for the storage of radioactive waste. The development of these materials is one of the vital problems of modernity. One of the promising such materials is the composites based on mica and glass (mikaleks).

Brief description of mica, its use. The first large-leaf mica that European civilization met was the mica of Karelia. In the XVII and early XVIII centuries, it was widely exported to the west from the Arkhangelsk port and was one of the most important export goods of Russia. The mica muscovite, which is now called light mica, is the name from Moscow or "Moscovia" [2, 3]. By the middle of the XVII century, an independent mica mining center in Siberia appeared. The role of local consumption of mica was large enough, and its extraction successfully developed. At the end of the 17th century, mica deposits were discovered in Aldan in the Mamsky District of the Irkutsk region [4-6]. Mica is one of the most common minerals in the earth's crust. The content of mica in the upper layers of the earth's crust is 2$4 \%$ of the total weight of rocks [3]. However, the world's industrial reserves are very limited. In $[7,8]$, the issues of extraction, processing, and properties of mica are quite thoroughly considered. Despite the wide distribution in nature of various micas, the greatest industrial importance is muscovite (potassium-aluminum mica) and phlogopite. Muscovite $\mathrm{KA}_{12}$ $\left[\mathrm{AlSi}_{3} \mathrm{O}_{10}\right](\mathrm{OH}, \mathrm{F})_{2}$, as impurities, contains $1-4 \%$ of $\mathrm{Fe}, 0.2-1.1 \%$ of $\mathrm{Mg}, 0.1-0.7 \%$ of $\mathrm{Na}$. Its color in thin plates is colorless and transparent, in thick - green, smoky, reddish (so called "ruby" mica). Phlogopite $\mathrm{K}(\mathrm{Mg}, \mathrm{Fe})_{3}\left[\mathrm{AlSi}_{3} \mathrm{O}_{10}\right](\mathrm{OH}, \mathrm{F})_{2}$ is painted in greenish-brown-amber (up to black) color. As impurities in it, $\mathrm{Na}, \mathrm{Mn}, \mathrm{Rb}, \mathrm{Cs}, \mathrm{Ba}, \mathrm{Li}$ are observed [9]. The most important properties of muscovite and floc-gopit are high mechanical strength, relatively high chemical and thermal stability, electrical strength, small dielectric losses, high specific, bulk resistance.

Fields of using mica. If for a long time the field of use of mica was the electrotechnical industry, now the range of mica use has significantly expanded: the construction industry, the paint and varnish industry, agriculture, cosmetology, medicine, etc. [10-13]. Only time can tell what new areas will cover mica and find its useful [14, 15].

Using mica for radiation protection. One of the promising areas of mica is its use as a material for radiation protection and disposal of radioactive waste. Substantial growth in production, energy, and transport create conditions in which a person is exposed to technological hazards due to the influence of various factors, the number of which is continuously growing. Radiation is one of them.

At present, there is no such branch of economy where radioactive materials are not used. Russia is the world leader in the use of nuclear energy, the energy of the future. It is necessary to create conditions for ensuring radio security. A large number of radioactive waste accumulates, and a problem arises in its utilization [16-18]. Protection from radiation is the main issue of radiation ecology. In this connection, the issue of developing new radiationresistant materials is of the highest importance.

It should be noted that one of the promising materials is mica, because mica and materials based on it have high radiation resistance. In addition, mica is not affected by acids, alkalis, moisture resistant, not expensive, and has good electrical insulating properties [8, 19]. The data on the effect of gamma-ray irradiation on the structure-phase transformations of biotite and hornblende are given in [20,21]. Electron irradiation was carried out on a linear accelerator KUT-1 of the NSC "KIPT" (electron energy: $\mathrm{E} \approx 7 \mathrm{MeV}$; average beam current: $\mathrm{I}=500 \mu \mathrm{A}$; irradiation temperature: $\approx 40^{\circ} \mathrm{C}$; infrared absorption spectra were studied in the frequency range of 400-4000 cm-10. With increasing irradiation dose, there is a consecutive increase in the intensity of the absorption band of $1620 \mathrm{~cm}-1$, related to deformation 
vibrations of the $\mathrm{O}-\mathrm{H}$ bond. There is some disordering of the crystal lattice, as a whole, mica flakes are not destroyed. Mica is a promising material for radiation protection. Changes in the refractive index, pleochroism, and the main IR absorption bands of hornblende are associated with a rearrangement in the octahedral sublattice caused by loss of structural hydroxyl groups and iron oxidation processes.

The production of materials for radiation protection based on mica is a common problem. Our research has shown that the promising material can be the composite material mikaleks being obtained by hot pressing of small-sized mica and low-melting glass, as a result of which a monolith with high electrophysical and mechanical properties is formed, which is not exposed to moisture, most acids, and can withstand complex processing [7, 8, 22]. The linear coefficients of attenuation of $\mu$ from gamma radiation of mikalexes of various compositions after bombardment by electron fluxes with an energy of $5 \mathrm{MeV}, 10 \mathrm{MeV}$, and $25 \mathrm{MeV}$ are studied. We used: a cesium source of $\gamma$-radiation with $\mathrm{E}=0.661 \mathrm{MeV}$ and cobalt with $\mathrm{E}=$ $1.25 \mathrm{MeV}$.

\section{Materials and methods}

Objective: to study the possibility of using composite materials based on mica for radiation protection, burial of radioactive waste, and for their operation in ultrahigh vacuum.

The object of the study: samples of selected composite material (mikaleks) based on muscovite and phlogopite mica, manufactured by hot forging mica deposits of fines and lowmelting glass with a content of $203(40 \%, 30 \%)$ [23].

$B y$ the method of recording the ionizing radiation and mass spectroscopic mi-caleses on the basis of various micas after bombardment of them with $5 \mathrm{MeV}, 10 \mathrm{MeV}, 25 \mathrm{MeV}$ electron beams. We used: a cesium source of $\gamma$-radiation with $\mathrm{E}=0.661 \mathrm{MeV}$ and cobalt with $\mathrm{E}=$ $1.25 \mathrm{MeV}$.

\section{Results and discussion}

The conducted tests of the linear attenuation coefficients $\mu$ on gamma radiation of mica-lexes of different composition after bombardment of them with $5 \mathrm{MeV}, 10 \mathrm{MeV}, 25 \mathrm{MeV}$ electron fluxes have shown that electron bombardment increases the penetrating power of gamma radiation in the mikalex. The change in the radiation intensity is determined from the law of attenuation of radiation:

$$
I=I_{0} e^{-\mu l}
$$

where $I_{0}$ is the intensity of the incident radiation, $I$ is the intensity of the transmitted radiation, $l$ is the thickness of the sample, $\mu$ - the coefficient of linear attenuation.

Figure 1 shows the experimental data of the coefficient of linear attenuation. As can be seen from Fig. 1, the best indicators are mikaleks based on phlogopite mica, a more heatresistant mica. The dehydroxylation of this mica is $150-200^{\circ} \mathrm{C}$ higher than that of muscovite $[7,8,24,25]$.

In $1 / 1$ '-phlogopite/muscovite is $70 \%$ + glass-30\%, 2/2'-phlogopite/muscovite- $60 \%+$ glass 203-40\%, depending on the radiation energy: a - cesium source, b - cobalt source of electrons.

A clear dependence of the coefficient of linear attenuation on the composition of the mikalex was revealed: the type of mica used, the percentage of mica, and the binding agent. A new field of use of composite materials based on mica (micalex) is recommended, as radiation-resistant materials and materials for the disposal of radiation waste. 
Mikaleks was tested for gas separation in ultrahigh vacuum. A sample of 20x20x3 mm was placed in an ultrahigh vacuum device USU-3. The unit was evacuated to a vacuum of $10^{-8} \mathrm{~mm} \mathrm{Hg}$. After reaching this limit, a 12-hour warm-up of the system was carried out together with the sample at a temperature of $10^{\circ} \mathrm{C}$. The cooled system was pumped down to $10^{-11} \mathrm{~mm} \mathrm{Hg}$. During the entire experiment, mass spectrometric monitoring of the composition of the residual gases was carried out. As a result of the experiments, it is found out that the presence of a sample in the system in no way affected either the pumping regime, the value of the maximum achievable vacuum, or the spectrum of residual gases. The conducted tests showed the possibility of using the products from the phlogopite mikaleks in ultrahigh vacuum as substitutes for ultrahigh-vacuum ceramics (UVC). Particularly valuable property of this material, in contrast to UVC, is the ability to withstand mechanical processing: drilling, milling, cutting. It is recommended to use this composite material in space.

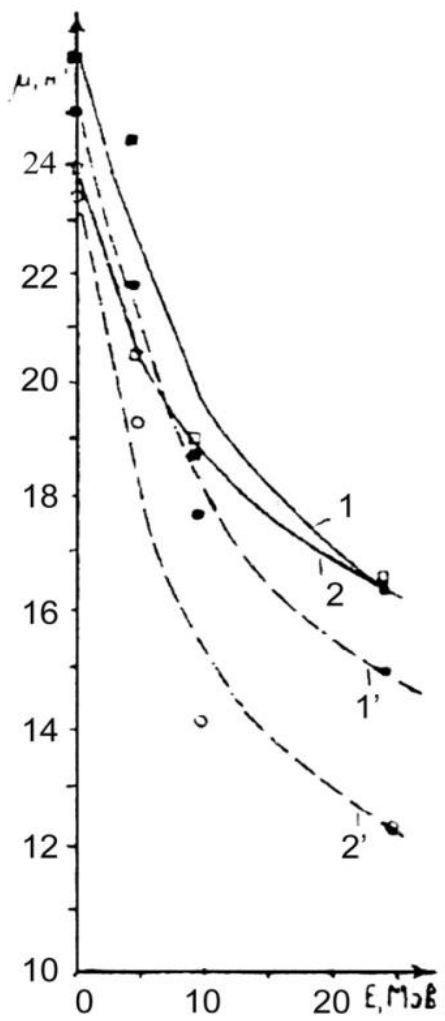

$a$

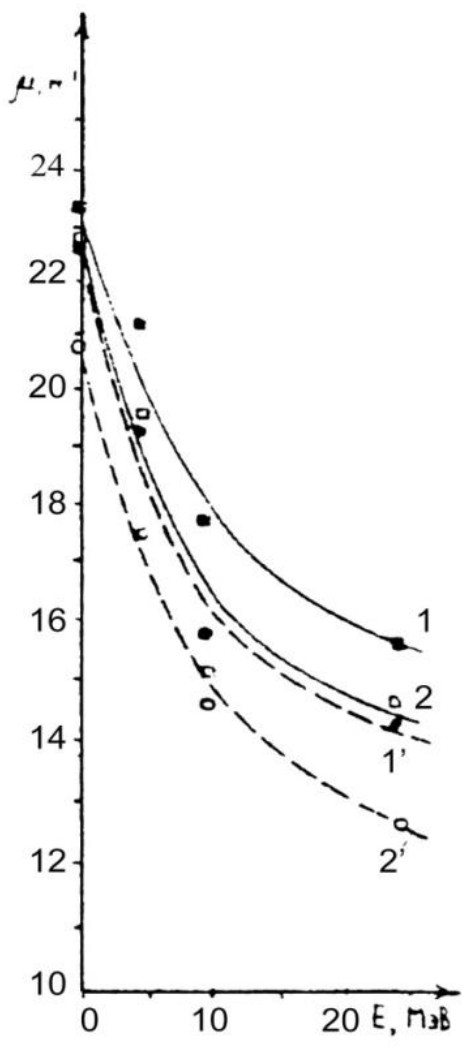

$\boldsymbol{b}$

Fig. 1. Dependence of the change in the linear attenuation coefficient $\mu$ on $\gamma$-radiation by electrons of different energies in accordance with the percentage content of the glass.

\section{Conclusion}

It was first experimentally established that a composite material based on mica and glass (mikaleks) can be used for radiation protection and burial of radioactive waste. Promising 
areas of using a composite material based on mica and glass for protection against radioactive emissions and for burial of radioactive waste in the construction industry are recommended.

\section{References}

1. RIA News (https://ria.ru/eco/20080923/151523253.html, 2008)

2. M. M. Shakhnovich, Izvestiya of the Irkutsk State University. Series: Geoarcheology. Ethnology. Anthropology, 9, 141-152 (2014)

3. A. Yu. Apsharov, Yu. E. Lytkina, S. B. Kurmangaliev, Science, education and innovation: proceedings of the intern. scientific-practical. conf. (Sterlitamak, 2017)

4. G. A. Yalovik, New and non-traditional types of deposits of useful excavated in Baikal and Transbaikalia: proceedings of the all-Russian scientific-practical conference, 315 (2010)

5. M. A. Vinokurov, A. P. Sukhodolov, Economics of the Irkutsk region (Irkutsk, 1999)

6. A. V. Tkachev, L. N. Sapozhnikova, Multifactorial models of deposits of sheet muscovite for poly-stage geological prospecting works. Granite pegmatites: problems of geological theory and practice (VIMS, Moscow, 2008)

7. T. I. Shishelova, V. V. Shulga, Journal of Basic Research, 3-3, 538-541 (2016)

8. T. I. Shishelova, N. G. Tyurin, E. A. Chaykina, S. B. Leonov, Physicochemical Foundations of Production of Mica Composites (Izd. LAD, Irkutsk, 1993)

9. K. I. Volkov, P. N. Zagibalov, M. S. Metsik, Properties, extraction and processing of mica (East-Sib., Izdatelstvo, Irkutsk, 1971)

10. S. R. Abdulova, N. M. Olakh, The interaction of science and society: problems and perspectives 22-23 (2016)

11. V. I. Bondarenko, G. V. Lukin, E. V. Samarkina, Herald of the IrGSCA, 51, 104-111 (2012)

12. I. O. Leushin, A. S. Lychagov, Blank Production in Machine Building, 8, 3-7 (2015)

13. V. B. Petrov, N. Yu. Glazova, Yu. G. Bychenya, Problems of rational use of natural and technogenic raw materials in the Barents region in construction and technical materials technology: proceedings of the international conference (2013)

14. M. C. Pazos, M. A. Castro, A. Cota, F. J. Osuna, E. Pavon, M. D. Alba, Journal of Industrial and Engineering Chemistry, 52, 179-186 (2017)

15. I. A. Serebryanik, S. V. Fedorova, Theoretical and Applied Science, 10, 20-23 (2015)

16. I. M. Neklyudov, E. P. Shevyakova, E. P. Bereznyak, V. L. Uvarov, L. A. Saenko, E. A. Borts. VANT: Series of Physics of Radiation Damage and Radiation Material Science, 4(89), 60 (2006)

17. V. A. Alekseenko, A. B. Ivanov, Geological and hydrological aspects of the problem of disposal of liquid radioactive wastes: materials III Mezhdunar. symposium on the disposal of RO (Ekaterinburg, 1995)

18. V. B. Dubrovsky, Radiation resistance of building materials (Stroyizdat, Moscow, 1977)

19. H. Sreenivasan, P. Kinnunen, E.-P. Heikkinen, M. Illikainen, Minerals Engineering, 113, 47-54 (2017)

20. E. P. Bereznyak, L. A. Saenko, E. P. Shevyakova, Herald of the KhNU, 915, 44-47 (2010) 
21. V. P. Ivanitsky, A. M. Kalinichenko, I. V. Matyash, DAN of the Ukrainian SSR, Ser. B, 7, 593 (1977)

22. T. I. Shishelova, L. V. Chilikanova, A. N. Konovalov, Advances in Modern Natural Science, 2, 87-88 (2004)

23. T. I. Shishelova, L. V. Chilikanova, V. G. Borzov, B. V. Bayborodin, T. I. Shishelova, Mikaleks (Publishing house of Irkutsk State University, Irkutsk, 1986)

24. T. I. Shishelova, E. L. Lipochenko, Successes of Modern Natural Science, 12, 177181 (2015)

25. T. I. Shishelova, N.V. Leonova, Successes of Modern Natural Science, 1, 23-27 (2017) 